\begin{tabular}{|c|c|}
\hline Massimo Corradi & Research \\
\hline Valentina Filemio & $\begin{array}{l}\text { Antonelli's Dome for San Gaudenzio: } \\
\text { Geometry and Statics }\end{array}$ \\
\hline $\begin{array}{r}\text { Dipartimento di Scienze per } \\
\text { l'Architettura } \\
\text { Università di Genova } \\
\text { Stradone di Sant'Agostino, } 37 \\
16123 \text { Genova ITALY } \\
\text { labmac@leonardo.arch.unige.it } \\
\text { Keywords: Alessandro Antonelli, } \\
\text { talian architecture, architectural } \\
\text { drawings, San Gaudenzio in } \\
\text { Novara, masonry domes }\end{array}$ & $\begin{array}{l}\text { Abstract. In this brief note the authors describe the studies } \\
\text { undertaken to date regarding the dome of the Basilica of San } \\
\text { Gaudenzio in Novara designed by Alessandro Antonelli, with } \\
\text { particular emphasis on the geometry and statics of the external } \\
\text { dome. Following a brief summary of the events and vicissitudes } \\
\text { attendant on the construction of the dome, the structure will } \\
\text { be examined from the point of view of the geometry, the } \\
\text { construction techniques, and the materials used, in order to } \\
\text { clarify the static behaviour and the stability of the whole set of } \\
\text { structural and constructive elements of which the dome is } \\
\text { composed. These studies have allowed us to obtain the } \\
\text { necessary information for evaluating the complex and } \\
\text { ambitious structural achievement of a significant element of } \\
\text { Antonelli's basilica. }\end{array}$ \\
\hline
\end{tabular}

\title{
The historical background
}

In order to introduce the reader to an in-depth understanding of the object of study presented here, we think it is important to precede the geometric and structural considerations with some brief notes on the history of the construction of the cupola of San Gaudenzio, built to a design by architect Alessandro Antonelli (1798-1888) between 1841 and 1878 [Rosso 1989].

The Basilica of San Gaudenzio was built on the highest point in Novara between 1577 and 1690, its original construction entrusted to Pellegrino Tibaldi, following instructions formulated by the Capitolo della Fabbrica and the ecclesiastic community [Peagno 1998a]. The construction of the monumental dome began much later, in 1841, and continued until 1878 . Work on the dome was accompanied by constant worries regarding the solidity and stability of the structure, giving rise to numerous interruptions, diatribes, investigations and inquiries aimed at evaluating whether or not Antonelli's project could actually be built. The construction went through four successive designs by Antonelli, who, taking advantage of a suspension of the work between the years 1851 and 1860, made significant formal and constructive revisions to his own initial project [Peagno 1998b]. In fact, Antonelli intended to construct a bold and majestic work, even though he knew how difficult it would be to obtain approval of a project so highly complex in terms of construction technology and statics, no matter how enlightened the committee was. In fact, his first project did not yet include the formidable arches that would be effectively constructed to support the dome.

In 1863 , construction had risen to the level of the thin-shell exterior dome, supported by a external double ring of granite columns (fig. 1). After yet another, prolonged suspension of the work, in 1876, the small lantern at the top was finally completed in 1878 . The statue of San Gaudenzio was placed at a height of some $125 \mathrm{~m}$ above the pavement of the church.

Nexus Network Journal 11 (2009) 243-256

NEXUS NETWORK JOURNAL - VOL. 11, NO. 2, 2009243

1590-5896/09/020243-14 DOI 10.1007/s00004-008-0082-1

(C) 2009 Kim Williams Books, Turin 

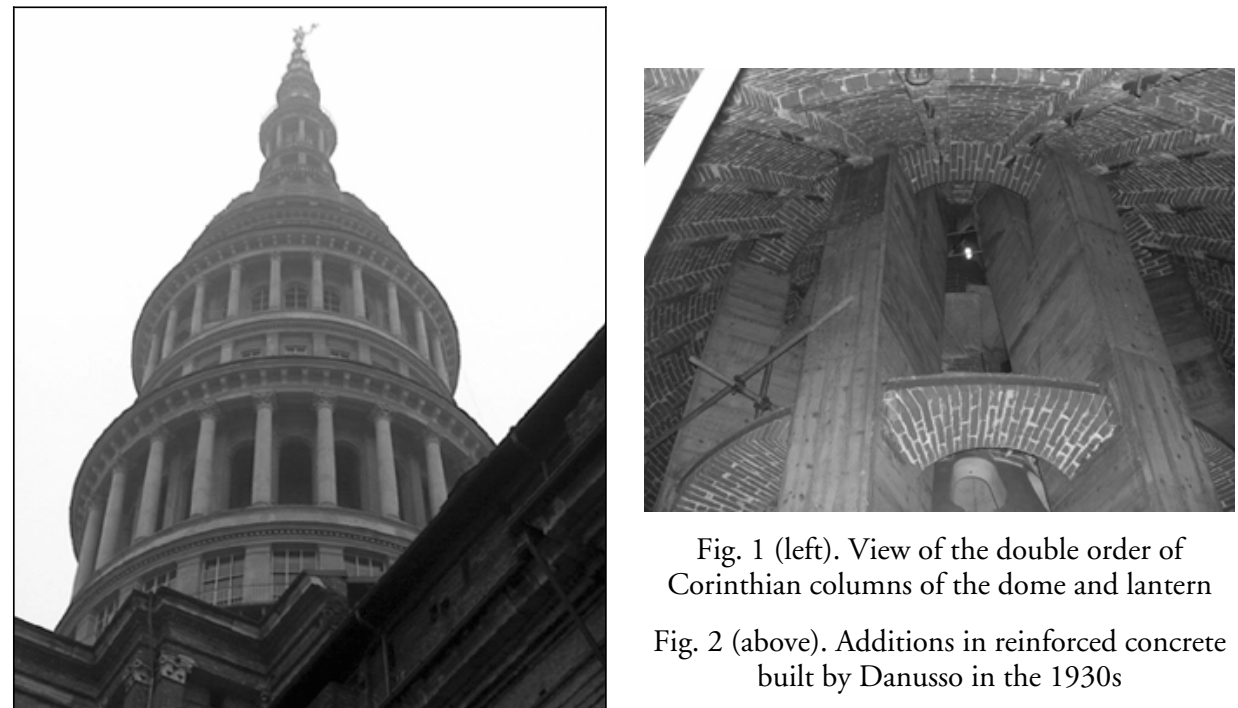

Fig. 1 (left). View of the double order of Corinthian columns of the dome and lantern

Fig. 2 (above). Additions in reinforced concrete built by Danusso in the 1930 s

In 1882, following the formation of some cracks in the flat arches that form the supporting skeleton of the drum of the cupola and the lower arches, the four piers that support the dome - part of Tibaldi's original work - were reinforced, or better, completely reconstructed, using a material and construction technique that were more reliable and in keeping with their intended function than the original ones.

In 1929, the observation of some cracks in the capitals of the first order of the lantern led engineer Arturo Danusso to alleviate the problem by applying a covering of reinforced concrete to the lantern and to the pilasters of the conic structure below it (fig. 2). This was complemented by the partial filling with concrete of the voids inside the piers that support the dome, with the aim of stabilizing the dome itself - also in danger of collapse - but at the cost of a considerable increase of weight [Pozzi 1997]. In any event, the new structure in reinforced concrete, when combined with the original one in brick, completely altered the original statical system, and in fact led to an infinite series of problems relating to the statics and the stability of the entire basilica, and raised questions about the feasibility of Antonelli's design that persist to the present day.

Following the interventions proposed and executed by Danusso and the persistence of phenomena related to the formation of widespread cracking, the basilica as a whole has been subjected to long-term and on-going monitoring with the aim of demonstrating the structural instability of Antonelli's project - an instability which, in fact, does not exist [Corradi 2000].

\section{Architecture and structure}

The dome of the Basilica of San Gaudenzio is noteworthy above all because of its monumental scale, with a height from the floor level of the church to its top of $125 \mathrm{~m}$, an internal diameter of $14 \mathrm{~m}$, and an external diameter of $22 \mathrm{~m}$, as well as for the daring of the forms and the complex constructive system, all of which make it unique in European architecture of the nineteenth century. It is also the highest masonry building in Italy.

244 M. Corradi, V. Filemio, M. TreneTTI- Antonelli's Dome for San Gaudenzio: Geometry and Statics 
Specifically, the study presented here concerned the exterior dome, that is, the portion of the structure that rises from a height of $65 \mathrm{~m}$, corresponding to the second order of exterior granite columns located at its base, up to $85 \mathrm{~m}$, the level of the base of the lantern. It is necessary to distinguish the interior (lower) dome from the exterior (upper) dome. The former is visible from the interior of the Basilica and is decorated with plaster coffers; the drum under it was encircled by a ring of reinforced concrete in the 1930s, part of the interventions of consolidation realized by Professor Danusso, with the aim of avoiding the "ovalisation" and implosion of the dome (fig. 3). The uselessness of this intervention has been recently demonstrated [Corradi and Filemio 2004].

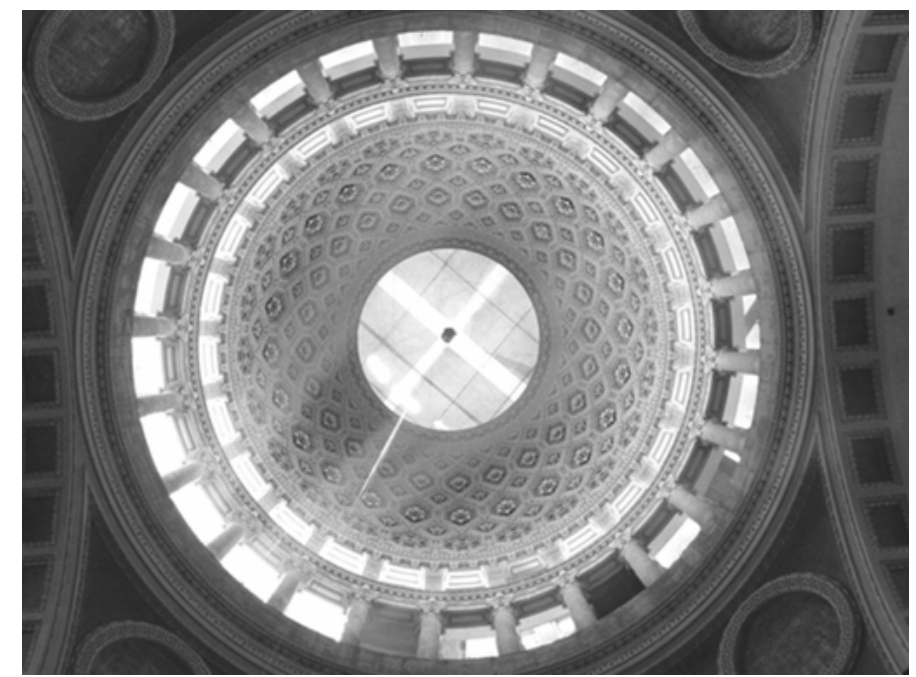

Fig. 3. View of the inner dome, the so-called "gran tazza", decorated with floral motifs and coffers, and of the ring in reinforced concrete built by Danusso at the level of the drum

The construction is daring and ambitious, especially since Antonelli designed and built a dome of such enormous scale with a thin structural shell only about $12 \mathrm{~cm}$ thick (the width a brick header) stiffened by ribs and compression rings - all in brick - arranged in a system of "meridians" and "parallels". This surface, stiffened in its turn both at the base by the ring of the drum and at the top by another ring in brick, conceals within itself another spectacular architecture, that is, a stiffening structure shaped like a truncated cone composed of a system of inclined brick pilasters placed on juxtaposed planes forming a grid with a circular base that decreases in diameter as it rises, joined to each other by a system of relieving arches (figs. 4 and 5). This structure constitutes the actual loadbearing skeleton designed by Antonelli, the element that is key for the statics and stability of the entire building.

Although the external dome and the internal structure are interconnected, they have in fact their own independent static behaviour, almost entirely consequent to different static stresses due to external forces and to the loads carried. These behaviours, however, are similar since each transmits its dead load through pre-established points and lines of force: the external dome by means of the ribs that subdivide it into wedges, the internal structure by means of the grid of pilasters and ribs of the truncated cone. On the other hand, the exterior dome, supported by the mighty arches at the base, resting in their turn on the large 
piers in the crossing of the nave, is in fact only a covering for the internal cone. The entire composition, combined with the lightness of the structural system and the inspired geometrical control of shape and light, testifies to a level of ambition and acumen found in few other buildings of the same time period [Benvenuto 1987].

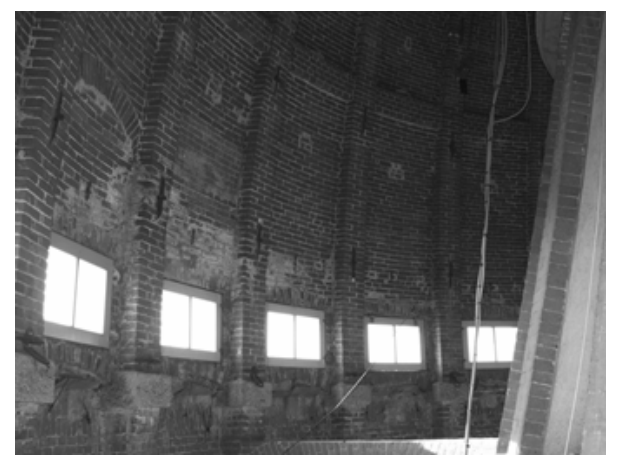

Fig. 4 (above). The system of internal and external ribs with granite dados, with the insertion of relieving arches and flat arches

Fig. 5 (right). The junction of the interior cone seen from below

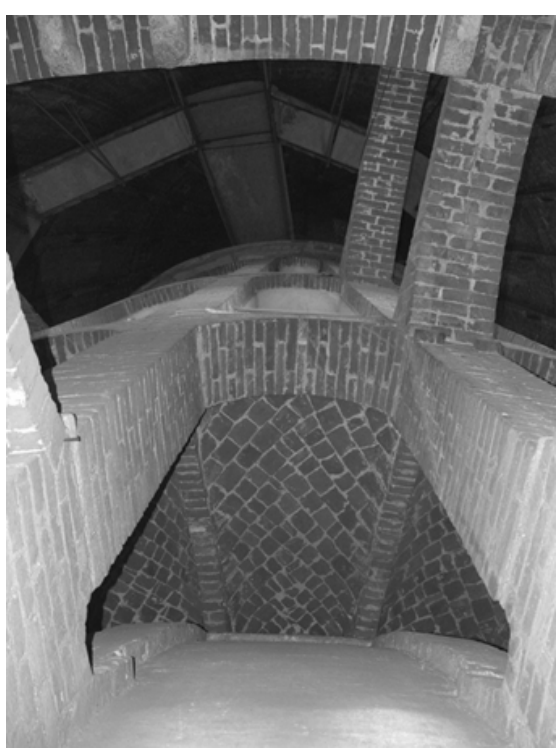

Our studies of the geometry have focused above all on the principal elements of the thin-shell dome, that is, the larger arch (the meridian) and the vault (the thin shell between two meridians). The meridians are stiffened by the complex system of rings along the parallels, and constitute the principal skeleton of the structure, while the vault is a thin shell, impalpable, almost ethereal. From a first examination of the structure the vault appears superfluous in terms of the statics in the stability of the whole but in reality it plays two distinct roles. The first is that of connecting the system of ribs like a membrane, following the meridians and parallels; the second is that of supporting the external covering, made up of slabs of schistose stone. In particular, the object of the present research was to identify by means of an analysis of different typologies of rotated surfaces (those belonging to families of conics such as the parabola, the catenary, etc.) which one effectively describes what happens in the dome. After a careful analysis of the dimensions, backed up an indepth instrumental survey of the geometry of the dome, we found that Antonelli relied on the circular arch to govern the execution of this magnificent architectonic object, a hypothesis validated by the existence of the compass actually used by Antonelli to trace the curve of the dome and to design the profile of the centering for the worksite. Still functioning today, the compass is housed in the so-called Sala del Compasso, located above the east transept of the basilica.

Further, noting that the curve of the dome in section is very acute, its height much greater than its width, our studies have aimed at revealing some sort of analogy with the methods used to lay out the arches and vaults of Gothic architecture, finding, if not a perfect analogy, at least a resemblance to the pointed lanciform arch. The profile of the lanciform arch is characterized by the fact that the generating radii of circular arches of the

246 M. Corradi, V. Filemio, M. TRENETTI- Antonelli's Dome for San Gaudenzio: Geometry and Statics 
dome are located at the level of the impost of the dome and have a diameter that exceeds the height of the object laid out, with a ratio equal to 1:0.80. We have found that the ratio of the diameter to height of the dome of San Gaudenzio is equal to 1:0.75. This leads to a displacement towards the exterior of the section of the centre of the layout and a curve that is even more acute than that of the Gothic.

The dome is thus a geometric form obtained by the rotation of a curve along the circumference of the base about its central axis, which is also the centre of gravity for the system of weights. It is therefore a rotated solid characterized by the perfect radial symmetry of the structure. Further, as surveys and studies undertaken on site have shown, the dome is not subject to phenomena of "ovalisation", since even though its diameter decreases as its height increases, it still remains a geometric figure characterized by perfect circularity at every horizontal plane, with infinite axes of symmetry and constant internal diameters.

\section{Construction technology}

The dome that covers the truncated cone structure is made up entirely of a single course of solid bricks and mortar forming a very thin shell (about $12 \mathrm{~cm}$ thick). The dome is supported by four double arches of different heights that spring from the same impost level but which are developed on different vertical planes and with variable slopes (oblique arches). The keystones, the imposts, and points just above the imposts are marked by the insertion between the bricks of stone blocks that correspond to the nodes of distribution of the stresses.

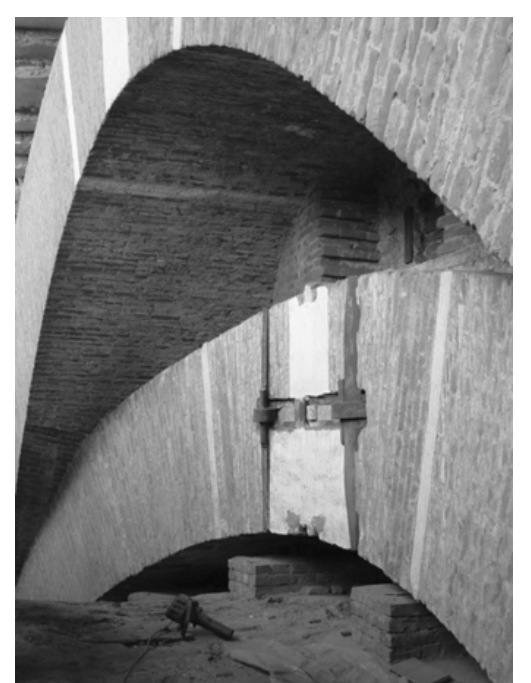

Fig. 6. Oblique arches that support the dome showing the stone blocks that stiffen them.

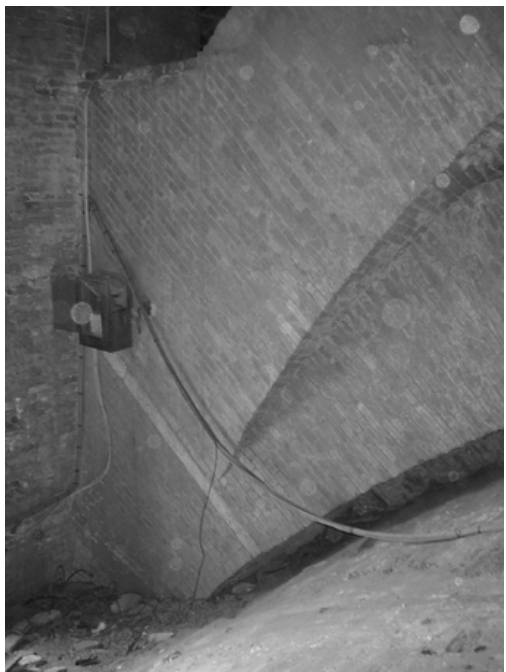

Fig. 7. Detail at the intersection of the two oblique planes of the arches

Further, in some courses the bricks are cut into wedge shapes and specially formed to follow the curve of the individual arches in order to guarantee the most suitable mechanical and material behaviour. On the exterior the dome rests on a double ring of monolithic Corinthian granite columns, which following Danusso's interventions lost their original static function of transmitting to the ground, like Gothic buttresses, the loads of the structure (figs. 6, 7). 


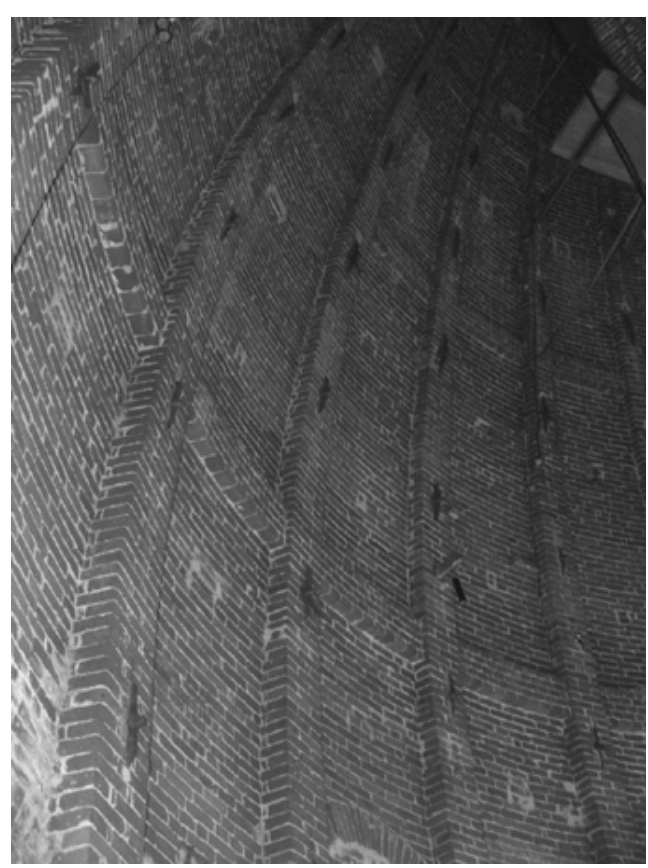

Fig. 8. A view from below of the external shell in brick stiffened by the system of ribs following "meridians" and "parallels". The dome, a shell only one brick header thick, is stiffened by a system of principal ribs (meridians) about a header and a half thick and of secondary ribs (parallels) one header thick
The skeleton of the dome is composed of thin ribs, or meridians (fig. 8) which, beginning from the impost of the dome (that is, from the top of the drum), rise up to the ring at the top of the thin shell. This upper ring, together with the lower ring at the drum, confers stability and stiffness to the exterior vaulting that covers the masonry skeleton of the ribs. The ribs rest on granite dados placed atop brick pilasters. The dados mark the transition from the vertical to the curved elements and ensure that the stresses that are transferred from the top of the dome to the impost of the pilasters and from there to the drum do not generate states of eccentric compressionbending stress outside the central core of inertia of the masonry section. In this way, the section, even though slightly in compression-bending, is subject only to forces of compression.

The ribs are connected to each other by a system of "chains", these also in brick, placed on three levels ("parallels") which give the dome the stiffness required to remain in a situation of stable equilibrium in the event of possible settling or failures due to horizontal forces such as wind or earthquakes.

These in fact translate into a series of compression rings that guarantee the stability of the thin shell, given its height and the thinness of the masonry. It should be further noted that the structure has been made even lighter by the opening of two series of circular and rectangular windows all along the perimeter of the dome, a feature for which Antonelli has often been criticized because it seemed to further weaken the masonry. In reality, the static equilibrium is maintained thanks to a continuous system of flat arches and relieving arches between the openings to guarantee the stability and stiffness of the masonry fabric.

At the impost of the exterior dome - as we said, at $65 \mathrm{~m}$ from the ground - is placed the $1 \mathrm{~m}$ wide catwalk of the dome, that is, a walkway in brick masonry that develops circularly along the vaults, supported at the intrados by a series of arches resting on granite corbels (fig. 9). This walkway functions as an internal chain, helping to ensure that the dome does not deform into an oval, thanks to its high degree of resistance to bending and to the complex static mechanism of which it is made. Further from this catwalk take off a ring of upside-down arches that connect it to the first dome on which rest the pilasters of the truncated cone.

248 M. Corradi, V. Filemio, M. TRENETTI- Antonelli's Dome for San Gaudenzio: Geometry and Statics 


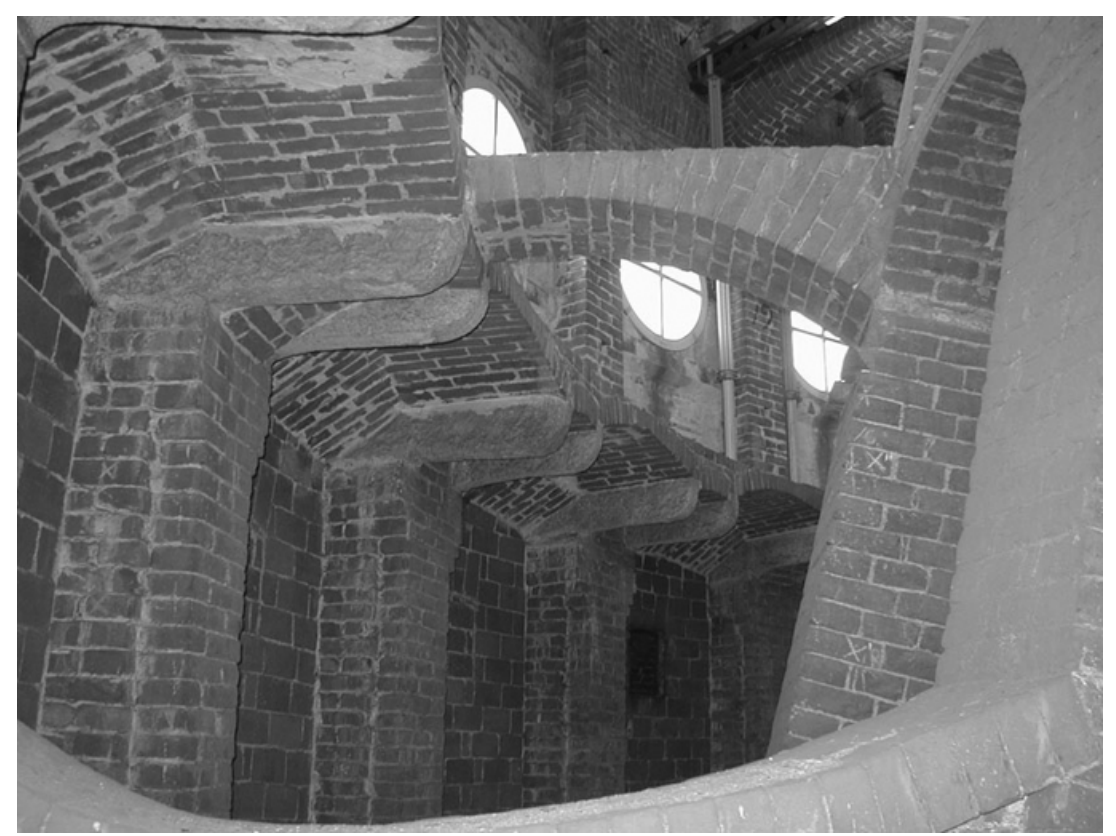

Fig. 9. Catwalk of the dome supported by granite corbels connected to the relieving arches

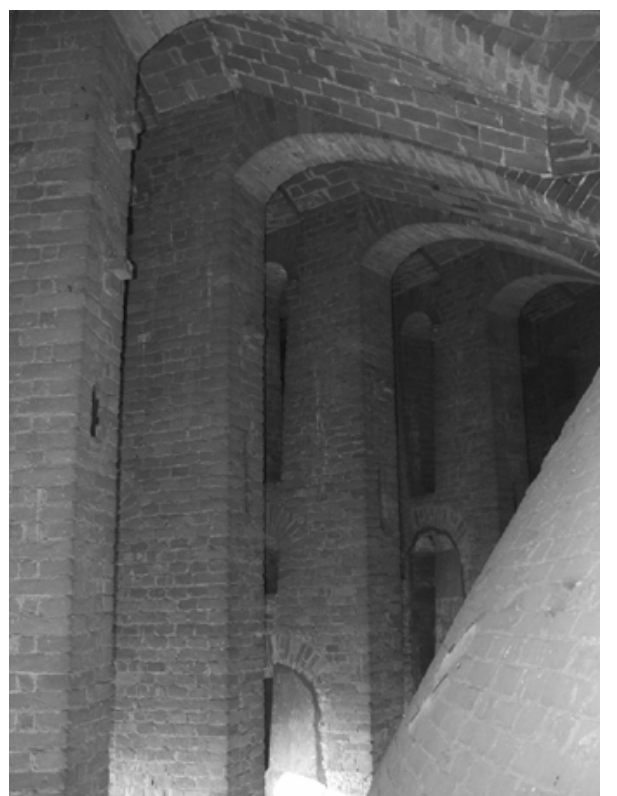

Fig. 10. system of climbing arches that support the catwalk above the interior dome

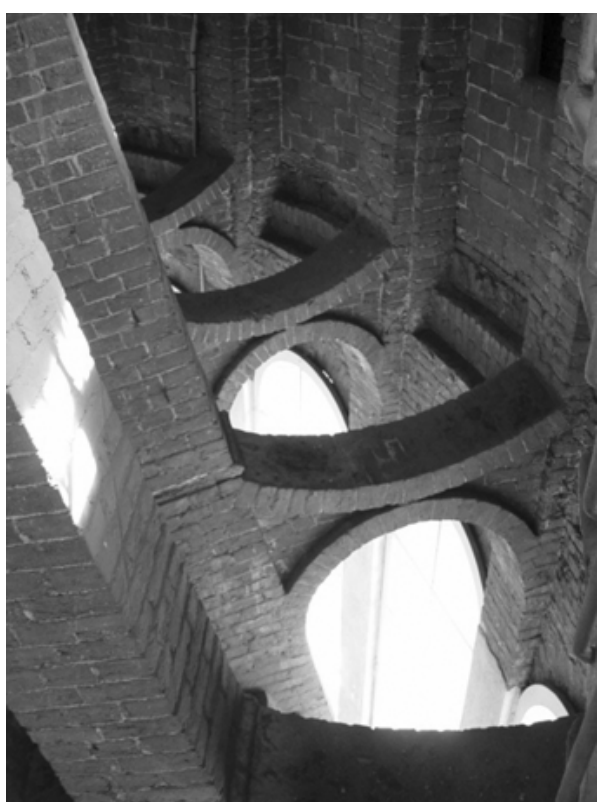

Fig. 11. View of the upside-down stiffening arches 


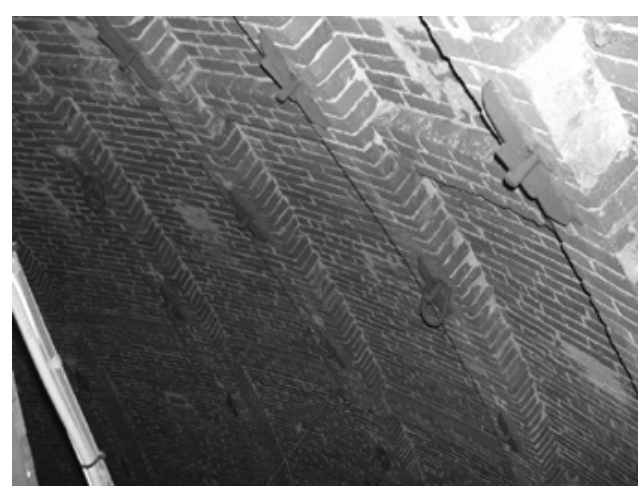

Fig.12. Ribs and supporting system of the external covering in stone slabs

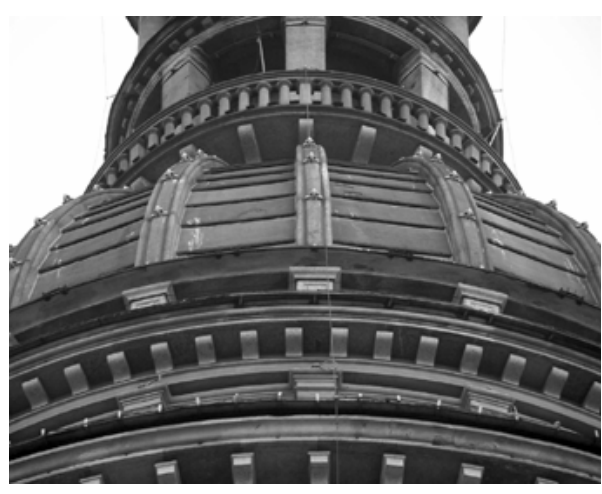

Fig.13. External covering: dados and restraining rings of the finishing in correspondence with the internal rib system

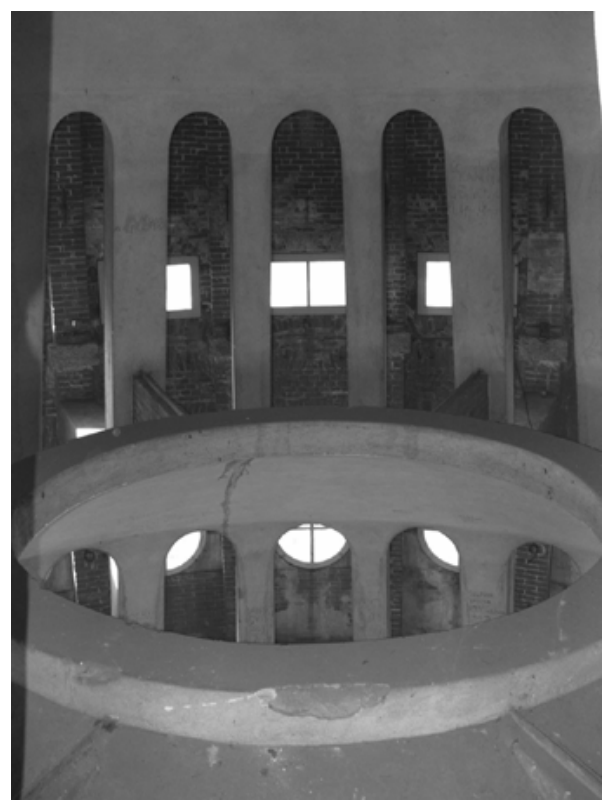

Fig. 14. Detail of Antonelli's "mechanism” under the exterior dome

The truncated cone structure, today entirely covered with cement, is composed of the system of pilasters forming the connection between three circular domes whose diameters decrease as they rise in height. The pilasters are connected and stiffened by brick arches and converge at the circular ring at the top of the dome, together with the ribs. That structure is connected to the dome by means of relieving arches in brick characterized in correspondence to the first dome, by a flat extrados and an intrados of flattened arches, which connect the individual pilasters to the corresponding ribs. Along the entire height of the cone is found a complex system of upside-down arches that connected to the outer dome (figs. 10, 11). 
As can be seen from this brief description, this is a complex masonry "mechanism" capable of resisting the set of horizontal and vertical forces - static and dynamic - to which the structure of the basilica is subject (figs. 12, 13, 14).

\section{Static behaviour}

The investigation of static behaviour and the stability of the dome focused on some of the principal aspects and particular elements of the structure, such as the arches of the interior dome and the external shell, visible from the interior of the vaults between the ribs, first taking them into consideration as individual structural elements and then as interconnected elements, evaluating within their sections the state of stress that results from the force of the loads and external forces of a static nature (that is, we have also considered the force of the wind and earthquakes).

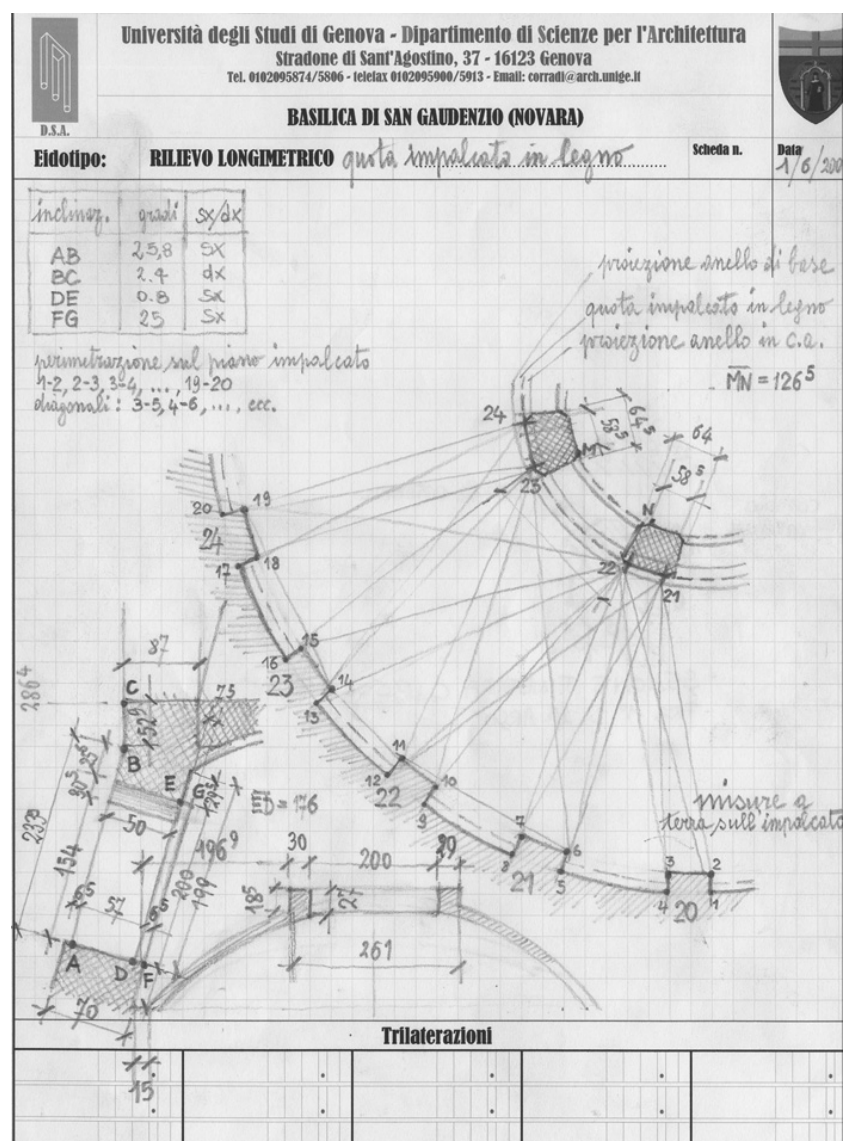

Fig. 15. Geometric triangulation (eidotype) 


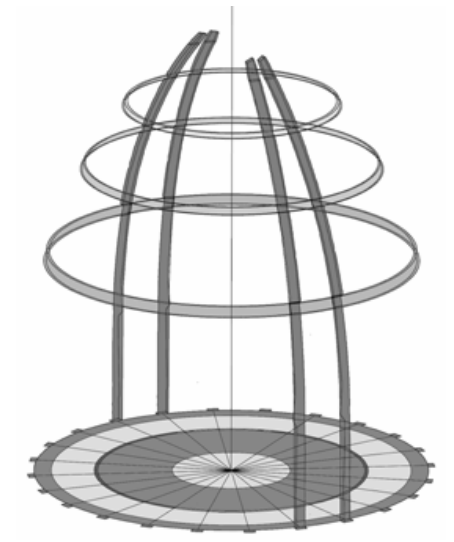

Fig.16. Schematic depiction of two symmetrical ribbed segments

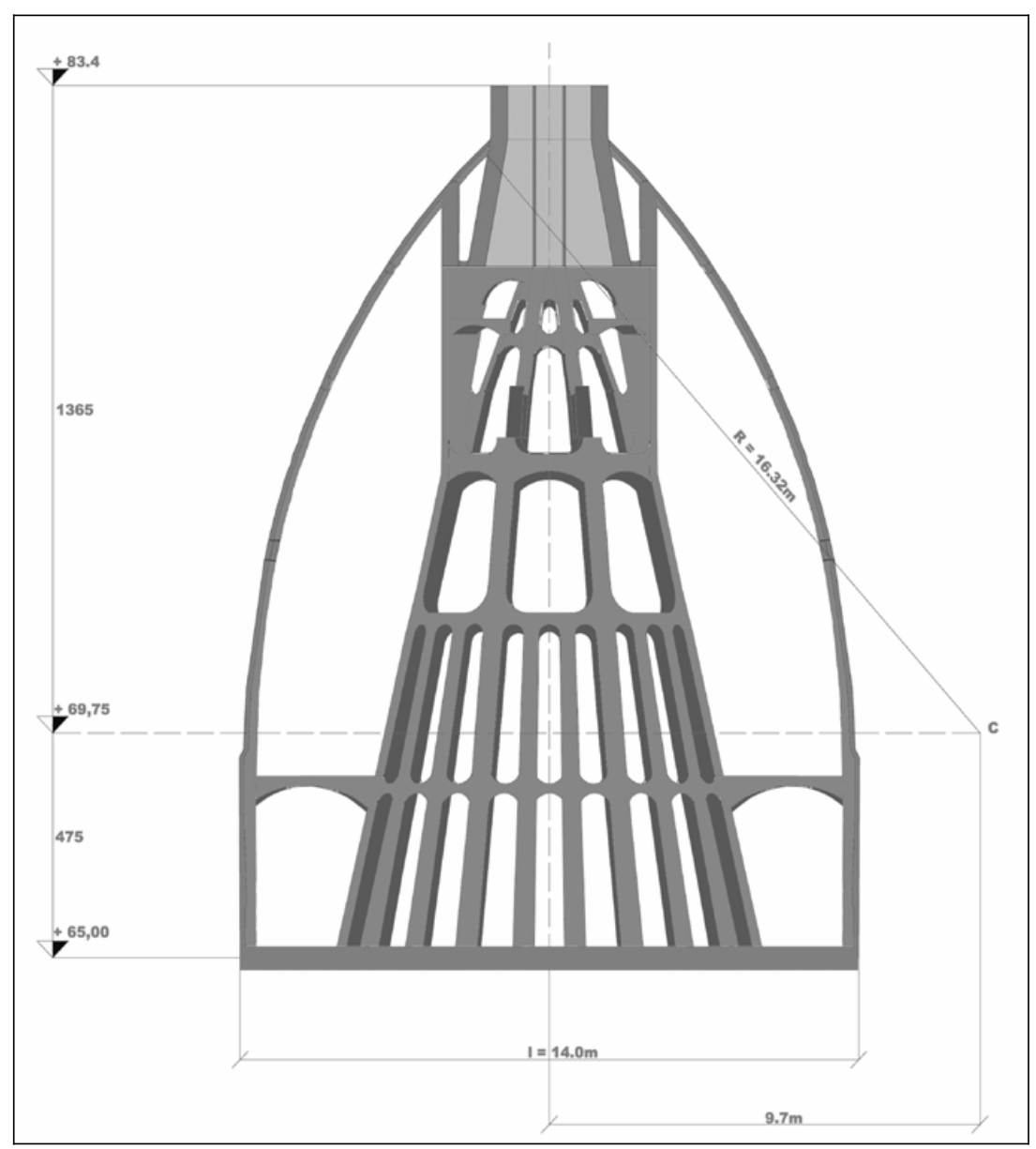

Fig. 17. Schematic depiction of the generating radius of the exterior dome

252 M. CorRadi, V. Filemio, M. TrenetTI- Antonelli's Dome for San Gaudenzio: Geometry and Statics 


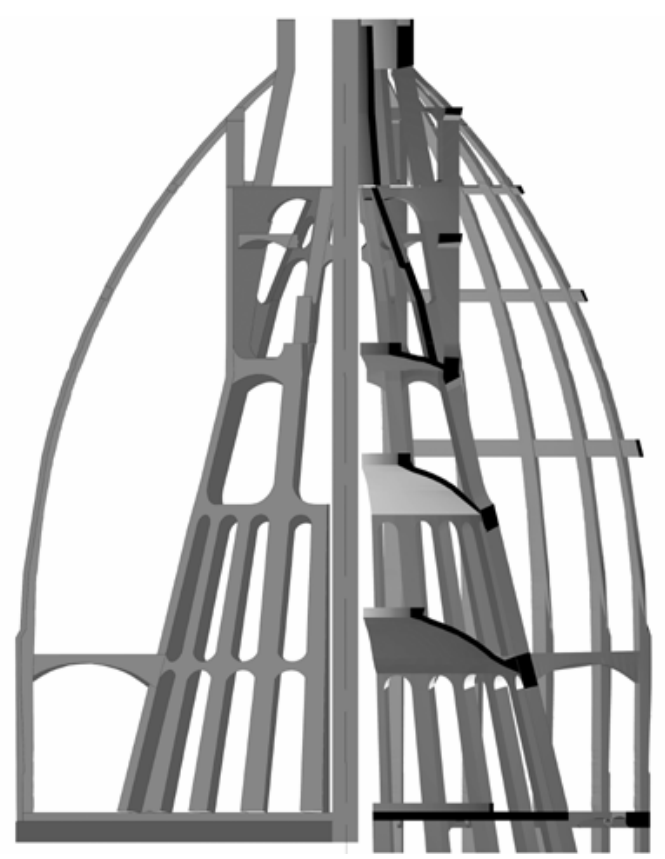

Fig.18. The section of the exterior dome and the interior cone

The modus operandi of our investigation was that of extrapolating the sections of the two structural elements by means of an accurate survey and an in-depth study of the geometry (figs. 15, 16) to determine the following: centres of gravity, the relative weights of individual blocks comprising the arch, the vaults, and the external shell (figs. 17, 18); the centres of stress; the kinematics of the thin shell as a whole stiffened by the ribs, and by the elements that connect the central cone as a function of the various kinds of stresses. The force diagram (by means of catenary and deformed elastic curves with limited rigid-plastic behaviour) and the resulting verification of the line of thrust curves and allowable deformations, useful for understanding the mechanical behaviour of the structure when subjected to various external forces, and, above all, the study of the states of tension within the resisting sections by means of the finite element method, with elements of eight nodes to identify the bricks and mortars, have demonstrated that the materials used in the construction are in fact adequate to resist the stresses.

The various investigations conducted on the structure of San Gaudenzio have shown that the shape of the line of thrust is perfectly contained within the masonry section of the dome, with only minimal variations - due to external forces, particularly the wind - from its intrados to its extrados, respectively from the keystone to the impost and vice versa. Further, a careful examination of the states of compound stresses has shed light on how, in particular load conditions (dead load), the behaviour of the dome as a thin shell, that is, capable of resisting bending, comes very close to the behaviour of a membrane. In fact, the shape of the arch of the median axis becomes a very similar to that of a segment of a catenary, with the geometric difference of an average quadratic deviation well below $1 \%$. 
The statical and mechanical analyses performed on the structural system of the dome as a whole have shown that up to the third parallel the structure is in fact only subject to compression, while below this level values of zero tension are measured at the intrados, with small values of tensile stress due almost entirely to numeric approximation. In any case, the values corresponding to maximum tension and minimum compression and tensile stress fall within the admissible range of resistance relative the materials used in the construction, that is, solid brick and mortar (fig. 19).

Finally, the study of the collapse kinematics are reminiscent of Poleni's notes regarding the stability of the dome of St. Peter's by Michelangelo.

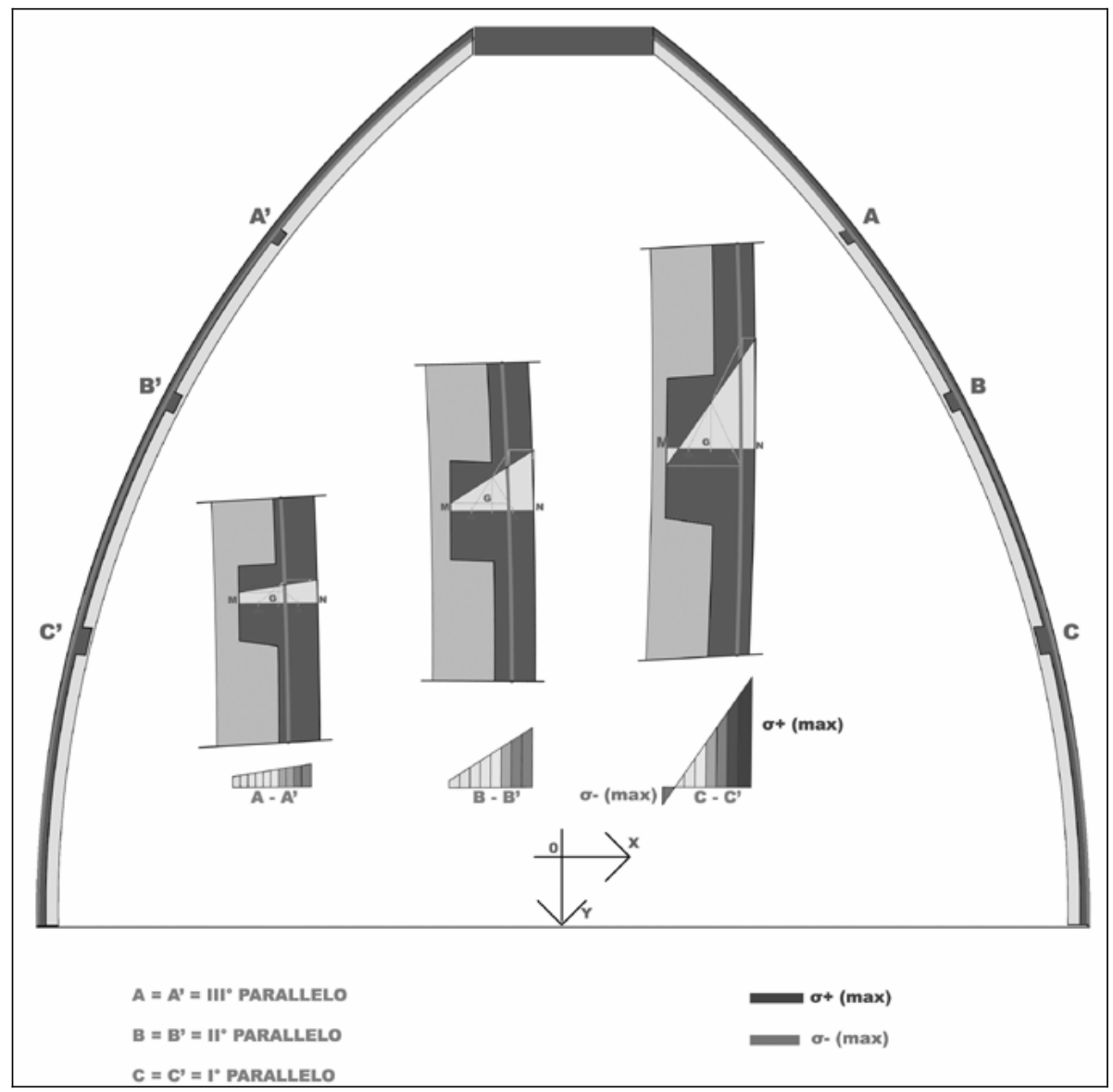

Fig. 19. Determination of the state of the principal stresses

\section{Conclusions}

The results obtained from the studies of the geometry and the mechanics of the dome of San Gaudenzio demonstrate how exceptional the structural system design by Antonelli is (fig. 20). It also demonstrates how such a grand and magnificent object can be in fact slender and light. The system used to stiffen the dome (comprised of the system of ribs

254 M. Corradi, V. Filemio, M. TRenetTI- Antonelli's Dome for San Gaudenzio: Geometry and Statics 
arranged along meridians and parallels, which connects the drum to the ring at the top) allows it to adapt to possible small variations of the initial state of equilibrium caused by failure and/or settling of the underlying structure or by external forces (wind, earthquakes) without incurring the risk of causing collapse kinematics. Further, if the brick dome seems astonishingly light, we should recall how Antonelli's masonry system, even though its main task is loadbearing, makes the various structural components evident and clearly distinguishes the principal from the secondary sustaining elements, relying on the primary system of vertical elements and the central cone for stability. Order and equilibrium govern and harmonize all the elements of the building, while a set of stiffening elements, embedded within the masonry itself, guarantees the invariability of the statical-mechanical system.

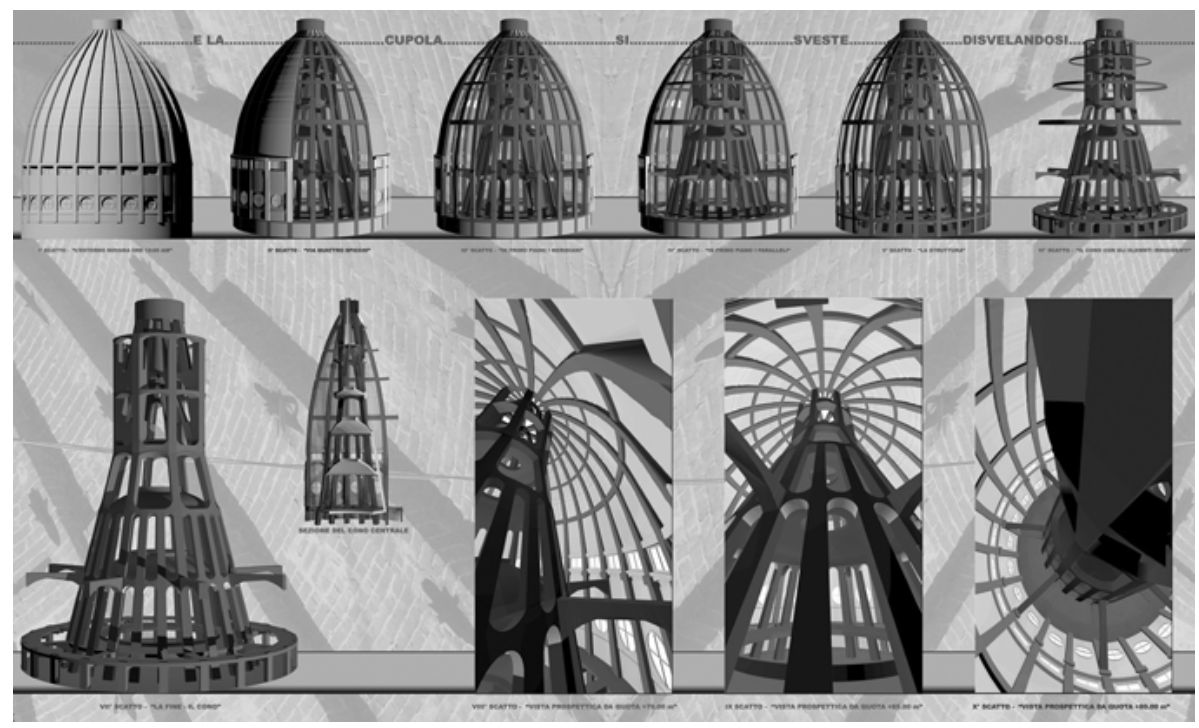

Fig. 20. Antonelli’s "mechanism"

Translated from the Italian by Kim Williams

\section{Acknowledgments}

The present study was conducted by the authors with the active collaboration of Massimo Trenetti who, as part of the preparation of his master's thesis in architecture, participated in the survey campaigns and the analyses in situ and was responsible for the drawings relative to the geometry of Antonelli's structure and the CAD drawings preparatory to the analysis of the statics. We also wish to thank Arch. Paola Pesce and Dr. Federica Lercari, specialists in the restoration of historic monuments, for their valuable and intelligent collaboration during the phases of the survey and the analysis of materials, Arch. Guido Peagno and Prof. Paolo Piantanida of the Politecnico di Torino, and all of the directors of the Fabbrica Lapidea of San Gaudenzio for their cordiality and helpfulness during the various phases of the work and for ongoing and helpful exchange of information on the history and constructive techniques of Antonelli's building. Finally we thank Kim Williams for the translation into English of the original Italian text. 


\section{References}

Benvenuto, E., et al. 1987. L'idee constructive en architecture. Paris: Picard.

Benvenuto, E. 1991. An Introduction to the History of Structural Mechanics. New York: Springer, vol. 2: pp. 349-371.

BianCOlini, D., ed. 1988. Il secolo di Antonelli, Novara. 1798-1888. Novara: Istituto Geografico De Agostini.

CORRADI, M. 2000. "Travailler à bien penser": alcune considerazioni sugli interventi di consolidamento della cupola di S. Gaudenzio a Novara. Pp. 297-308 in La prova del tempo. Verifiche degli interventi per la conservazione del costruito, G. Biscontin and G. Driussi, eds. (Proceedings of the congress "Scienza e Beni Culturali, XV, 2000", Bressanone 27-30 June 2000). Venice: Arcadia Ricerche.

Corradi, M. and V. Filemio. 2004. Il cemento armato e la Basilica di S. Gaudenzio a Novara, ovvero: il restauro statico regolato dall'ideologia della 'soggettività', Pp. 231-239 in La prova del tempo. Verifiche degli interventi per la conservazione del costruito, G. Biscontin and G. Driussi, eds. (Proceedings of the congress "Scienza e Beni Culturali, XV, 2000", Bressanone 27-30 June 2000). Venice: Arcadia Ricerche.

CRENNA. M., ed. 1983. La cupola di San Gaudenzio. Una struttura verso l'alto. Novara: Istituto Geografico De Agostini.

DAverio, A. 1940. La cupola di S. Gaudenzio. L'opera del massimo architetto italiano del secolo XIX Alessandro Antonelli. Novara: Centro studi antonelliani.

GabetTI, R. 1962. Problematica antonelliana. Pp. 159-194 in Atti e rassegna tecnica della Società degli Ingegneri e degli Architetti in Torino. Turin: Società degli Ingegneri e degli Architetti.

Mongiat, E., ed. 1986. Conosciamo la Novara antonelliana. La Cupola della Basilica di San Gaudenzio. Novara: Tipografia Artigiana.

Peagno, G., ed. 1998a. L'opera dell'architetto Pellegrino Pellegrini detto il Tibaldi, Atti del convegno. Novara: Tiponova s.r.l.

Peagno, G., ed. 1998b. Per San Gaudenzio. Ravenna: Valerio Maioli. (Revised ed. of [Daverio 1940].)

POZZI, R. 1997. Arturo Danusso e il consolidamento della cupola di San Gaudenzio a Novara. Ananke 17/18: 101-110.

Rosso, F., ed. 1989. Alessandro Antonelli: 1798-1888. Milano: Electa. (Catalogue of the exhibit held in the Mole Antonelliana in Turin, 8 June-15 October 1989.)

Temporelli, A. and D. Tuniz. 1984. San Gaudenzio e la sua basilica. Borgosesia: Edizioni Palmiro Corradini

ZINGARIELLO, I. 1985. Antonelli ultimo mago del mattone. Scienza \& Vita nuova VII, 7 (July 1985): $112-113$ and $117-119$.

\section{About the authors}

Massimo Corradi is associate professor in history of sciences, teaches the courses in the history of construction science and techniques, and directs the Laboratory of Mechanics applied to Structures in the Faculty of Architecture at the University of Genova.

Valentina Filemio holds a degree in "Conservazione dei Beni Culturali" with a specialisation in "Restauro dei Monumenti", and completed work on her doctorate in "Storia e valorizzazione del patrimonio architettonico, urbanistico e ambientale" at the Politecnico di Torino in 2008. She collaborates on research projects about the history of science and the relationships between architecture and structure in historic buildings.

Massimo Trenetti holds a degree in architecture, and collaborated with the Department of Architectural Sciences at the University of Genova during the studies conducted on the dome of San Gaudenzio.

256 M. Corradi, V. Filemio, M. TRENETTI- Antonelli's Dome for San Gaudenzio: Geometry and Statics 